\title{
A new slick water system for hydraulic fracturing in tight reservoir to enhance imbibition oil recovery
}

\author{
$Y u$ Haiyang $^{1 *}, J i$ Wenjuan $^{2 *}$, Luo Cheng $^{3}$, Lu Junkai ${ }^{3}$, Yan $\mathrm{Fei}^{3}$, Liu $\mathrm{Yi}^{3}$, and $W u \mathrm{Jun}^{3}$ \\ ${ }^{1}$ College of Energy and Mining Engineering, Shandong University of Science and Technology, \\ Qingdao, Shandong, 266590, China \\ ${ }^{2}$ Shandong Key Laboratory of Oilfield Chemistry, China University of Petroleum (East China), \\ Qingdao 266580 \\ ${ }^{3}$ Jidong oilfield, CNPC, Tangshan, Hebei, 063000, China
}

\begin{abstract}
In order to give full play to the role of imbibition of capillary force and enhance oil recovery of ultralow permeability sandstone reservoir after hydraulic fracturing, the mixed water fracture technology based on functional slick water is described and successfully applied to several wells in oilfield. The core of the technology is determination of influence factors of imbibition oil recovery, the development of new functional slick water system and optimization of volume fracturing parameters. The imbibition results show that it is significant effect of interfacial tension, wetting on imbibition oil recovery. The interfacial tension decreases by an order of magnitude, the imbibition oil recovery reduces by more than $10 \%$. The imbibition oil recovery increases with the contact angle decreasing. The emulsifying ability has no obvious effect on imbibition oil recovery. The functional slick water system considering imbibition is developed based on the solution rheology and polymer chemistry. The system has introduced the active group and temperature resistant group into the polymer molecules. The molecular weight is controlled in 1.5 million. The viscosity is greater than $2 \mathrm{mPa} \cdot \mathrm{s}$ after shearing $2 \mathrm{~h}$ under $170 \mathrm{~s}^{-1}$ and $100^{\circ} \mathrm{C}$. The interfacial tension could decrease to $10^{-2} \mathrm{mN} / \mathrm{m}$. The contact angle decreased from $58^{\circ}$ to $22^{\circ}$ and the core damage rate is less than $12 \%$. The imbibition oil recovery could reach to $43 \%$. The fracturing process includes slick water stage and linear gel stage. $10 \% 100$ mesh ceramists and $8 \%$ temporary plugging agents are carried into the formation by functional slick water. 40-70 mesh ceramists are carried by linear gel. The liquid volume ratio is about $4: 1$ and the displacement is controlled at $10-12 \mathrm{~m}^{3} / \mathrm{min}$. The sand content and fracturing fluid volumes of single stage are $80 \mathrm{~m}^{3}$ and $2500 \mathrm{~m}^{3}$ respectively. Compared with conventional fracturing, due to imbibition oil recovery, there is only $25 \%$ of the fracturing fluid flowback rate when the crude oil flew out. When the oil well is in normal production, about $50 \%$ of the fracturing fluid is not returned. It is useful to maintain the formation
\end{abstract}

*Corresponding author: yhy skd@,sdust.edu.cn; jwj1224@126.com;

luocheng@petrochina.com.cn 
energy and slow down the production decline. The average cumulative production of vertical wells is greater than $2800 \mathrm{t}$, and the effective period is more than 2 years. This technology overcoming the problem of high horizontal stress difference and lack of natural fracture has been successfully applied in Jidong Oilfield ultralow permeability reservoir. The successful application of this technology not only helps to promote the effective use of ultralow permeability reservoirs, but also helps to further clarify the role of imbibition recovery, energy storage and oil-water replacement mechanism.

\section{Introduction}

Effect of surfactants on Imbibition oil recovery.

Slick water fracturing fluid is defined as adding a certain amount of proppants and a very small amount of additives, such as surfactant, friction reducing agent and antiswelling agent in the water. Slickwater early in 1950 has been used in the development of oil and gas reservoirs, but is replaced quickly by the subsequent developed cross-linked polymer fracturing fluid. But with the rapid development of unconventional oil and gas reservoirs, slickwater is applied to the fracturing technology again. In 1997, Mitchell energy company used slickwater in Barnett shale gas fracturing and achieved good results ${ }^{[1]}$. Since then, slickwater fracturing is widely used in shale gas development in the United States. By the end of 2004, slickwater fracturing fluid volume has accounted for more than $30 \%$ of the total amount of the fracturing fluid ${ }^{[2]}$. The slickwater fracturing without proppant would lead to poor conductivity and low yield. Field application results show that slickwater fracturing with a certain proppant can improve conductivity obviously and enhance production and recovery efficiency of single well ${ }^{[3,4]}$. At present, in addition to water and proppant, there is a small amount of additives in the slickwater fracturing fluid and the total content is below $1 \%{ }^{[5]}$. Although the content is low, these additives play an important role. In recent years, more and more people have studied the effect of surfactants on the imbibition oil recovery of tight oil and gas reservoirs. And the surfactant in slickwater system is how to influence the imbibition oil recovery. SHULER P J through experiment research shows that the addition of nonionic and anionic surfactants in the fracturing process can improve the oil recovery of Bakken shale ${ }^{[6]}$. The research of WANG D from Bakken and Bakken on shale samples shows that surfactants can change the wettability of rock samples and increase the recovery of crude oil ${ }^{[7]}$. The effect of anionic surfactants is better than that of the amphoteric ionic surfactants and non ionic surfactants. The oil displacement effect of anionic surfactants and nonionic surfactants in a certain unconventional oil and gas reservoir shows that anionic surfactants in the initial system of weak water wetting can increase the contact angle, while a nonionic surfactant doesn't change in the contact angle ${ }^{[8,9]}$. In tight sandstone reservoirs, ultra-low permeability restricts the flow of fluid in the reservoir, and enhance imbibition oil recovery is one of the methods to improve the recovery. Imbibition is defined as using water to replace the crude oil in the matrix in a water wetting reservoir. The motive force of spontaneous imbibition is capillary force, gravity and viscous force. Once the matrix-fracture interaction is enhanced and the effective path of oil and gas flow to the wellbore is created, spontaneous imbibition becomes an important mechanism for oil and gas exploitation. From the capillary force formula, the tight reservoir has nanometer pore size, which will increase the capillary pressure of crude oil bound to the matrix, thus limiting the successful application of the 
primary recovery method. The surfactant could be used to change wettability of the reservoir, reduce the capillary force and strengthen imbibition effect, which could be enhanced the oil recovery. The surfactant is a two parent compound with hydrophobic and hydrophobic groups. The surfactant into the matrix of the reservoir rocks can change the wettability and reduce the capillary pressure because of decreasing interfacial tension. The researchers propose three main mechanisms to change the wettability: ion pair formation ${ }^{[10]}$, surface active agent adsorption ${ }^{[11]}$ and micellar solubilization ${ }^{[12]}$.

The slickwater system is one of the key technologies in the volume fracturing. The most commonly used slickwater system includes polymer type ${ }^{[13]}$, surfactant type ${ }^{[14]}$, nano composite ${ }^{[15]}$ and biological polysaccharide type ${ }^{[16]}$. At present, in the process of application of slickwater, imbibition recovery is seldom considered. In this paper, based on the analysis of influence factors of imbibition, a novel functional slickwater is developed and applied in the hydraulic fracturing to enhance imbibition oil recovery.

Usually, the surfactant is added to the fracturing fluid as a cleanup agent to increase the flowback rate of the fracturing fluid. The interfacial tension of the fracturing fluid is less than $2 \mathrm{mN} / \mathrm{m}$ according to the standard. But with the fracturing development of ultra-low permeability and tight oil reservoirs, besides making fracture and carrying sand, the fracturing fluid also has the effect of increasing the rate of imbibition oil recovery and supplementation of energy. The enhancement of imbibition recovery in the process of fracturing is closely related to the surfactant in the fracturing fluid system. The relationship between interfacial tension, wettability, emulsification and imbibition recovery is analyzed by static imbibition in order to optimization of a new fracturing fluid system.

The steps of the static imbibition experiment are as follows: Firstly, determination of core porosity and permeability by conventional physical methods after natural core cleaning. The core is evacuated to $0.1 \mathrm{MPa}$ in the formation water until there is no bubble. And it is displacement by crude oil until there is no water flow out from the core. Aging $48 \mathrm{~h}$ at formation temperature after calculating irreducible water saturation. The aged core is placed in a volume imbibition instrument, and different liquids are placed into the measurement scale to record the volume of imbibition oil under different time. In the process of experiment, it is existed "threshold jumping" and "hanging wall phenomenon". This would lead to the error of the relationship between the imbibition recovery and the time. The experiment only records the final imbibition recovery and neglects the imbibition process.

In the experiment, the core is from a certain oilfield, buried depth from $3595 \mathrm{~m} \sim 3599 \mathrm{~m}$, size: diameter $2.5 \mathrm{~cm}$, length $5.5 \sim 9.3 \mathrm{~cm}$, permeability $3 \mathrm{mD}$, strong water-wetting. The experimental oil is a mixture of real crude oil and kerosene, the viscosity $2.5 \mathrm{mPa} \cdot \mathrm{s}$ at $50^{\circ} \mathrm{C}$, the interfacial tension with formation water $21 \mathrm{mN} / \mathrm{m}$, the density $0.825 \mathrm{~g} / \mathrm{cm}^{3}$. The salinity of experimental water is $6000 \mathrm{mg} / \mathrm{L}$, Sodium bicarbonate water type. The experimental concentration of the surfactant is the critical micelle concentration.

Interfacial tension vs imbibition oil recovery

Determination of imbibition recovery of surfactant solution under different interfacial tension, fig. 1 . The interfacial tension is range from $10^{-3} \mathrm{mN} / \mathrm{m}$ to $10^{1} \mathrm{mN} / \mathrm{m}$. The results show that with interfacial tension increasing, the imbibition oil recovery increases. when the interfacial tension is larger than $10^{-1} \mathrm{mN} / \mathrm{m}$, the increase of imbibition oil recovery is smaller and gradually tends to be slow. Based on this experiment result, the optimal interfacial tension of fracture fluid settle in approximate $10^{-1} \mathrm{mN} / \mathrm{m}$. At the same time, with the decrease of interfacial tension, the time of final imbibition recovery needed is getting longer and longer. The capillary force formula shows that with the decrease of interfacial 
tension, the capillary force decreases under the same condition. It would result in a decrease in the power of the imbibition oil recovery, which leads to the reduction of the imbibition recovery and prolong the time needed for imbibition.

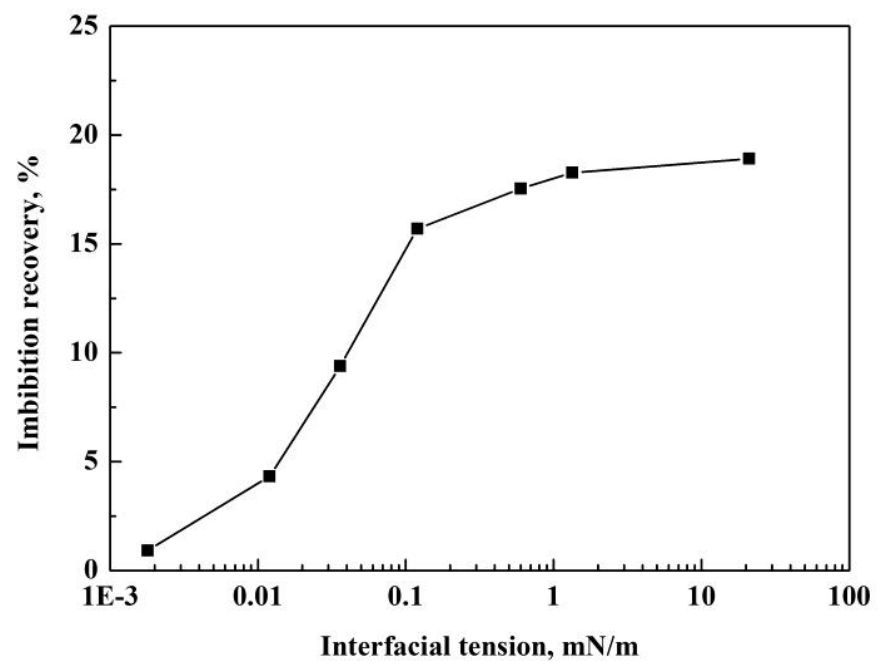

Fig. 1. the interfacial tension vs imbibition oil recovery

Wettability vs imbibition oil recovery

Contact angle is one of the methods to indicate wettability. The change of wettability can be achieved by adjusting the contact angle. The contact angle is defined as the tangent angle of the oil-water interface at the intersection point of the rock sample. When the contact angle is $0^{\circ}$, the water will wetted evenly on the surface of the solid. With contact angle increasing, the formed water droplets will wetting the solid surface at a specific angle. When the contact angle is $180^{\circ}$, the water will not wetting the solid surface. In the experiment, a dynamic contact angle measuring instrument was used to test the quartz slices of distilled water after soaking in different surfactant solutions. The contact angle of the distilled water on the surface of the clean quartz is about $35^{\circ}$. The influence of wettability on imbibition is determined by analyzing the relationship between the change of contact angle and the imbibition oil recovery, fig. 2 


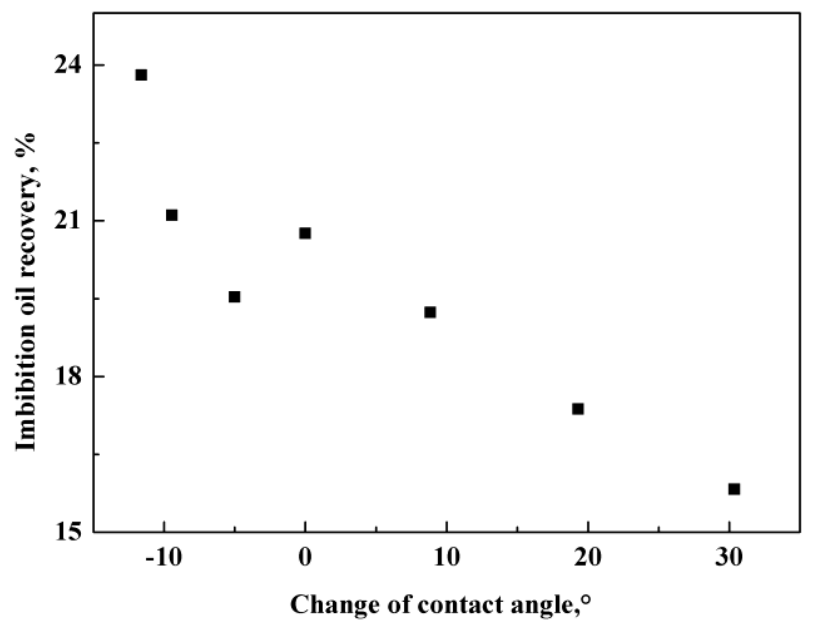

Fig. 2. the change of contact angle vs imbibition oil recovery

The change of contact angle $0^{\circ}$ is the wettability of distilled water, whose imbibition oil recovery is $20.7 \%$. When the change of contact angle is less than $0^{\circ}$, which shows that the surfactant can change the reservoir to be more water-wetting. With water-wetting increasing, the imbibition oil recovery increases. When the change of contact angle is greater than $0^{\circ}$, which shows that the surfactant can change the reservoir to be more oilwetting. The imbibition oil recovery decreases with oil-wetting increasing. There is a close relationship between the size of the capillary force and the wettability of the reservoir. The water-wetting is enhanced and the capillary force increases. On the contrary, the oil-wetting is enhanced and the capillary force is reduced. It can be seen that the fracturing fluid system can change the original state of the reservoir to water-wetting, which is beneficial to the enhancement of the imbibition oil recovery.

Emulsifying ability vs imbibition oil recovery

Emulsifying ability is one of the important properties of surface active agent, which is influenced by interfacial tension, shear force, property of boundary film and so on. The emulsification performance could produce two enhanced oil recovery functions. One is the action of emulsification and the formation of emulsion, which will bring the crude oil to carry out; the another one is the emulsifying profile control effect, preferentially entering the large channel with small resistance. The cumulative Jamin effect will play a role of plugging and increase the sweep efficiency. A fast stirring method is used to mix the oil and water fully, and then the amount of water separation is recorded for 30 minutes. The proportion of crude oil and water solution is $1: 1$. The relationship of water separation rate and imbibition oil recovery is established, fig.3. 


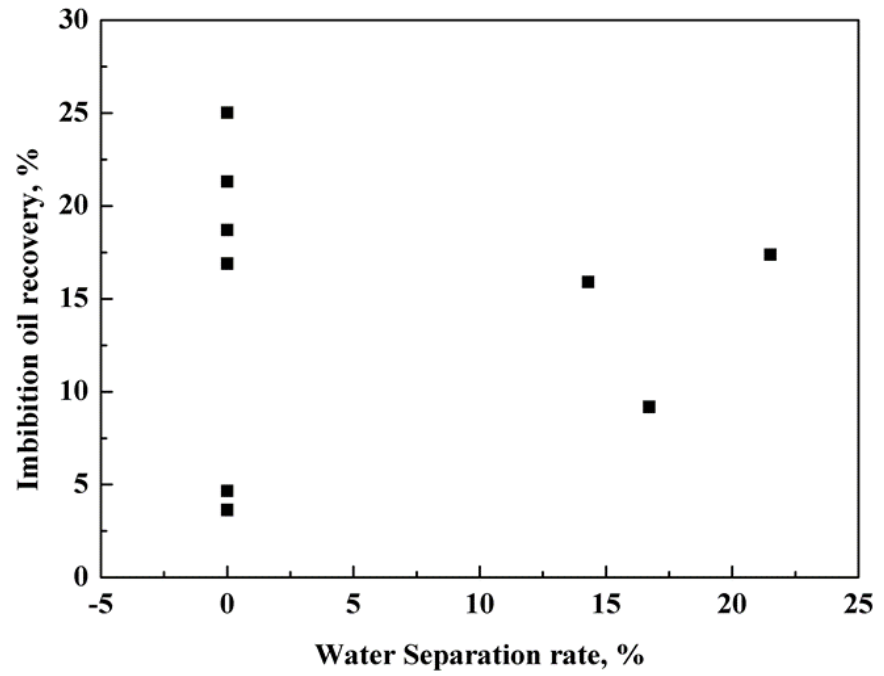

Fig. 3. the water separation vs imbibition oil recovery

The imbibition recovery of the surfactant without emulsification is from $3 \%$ to $25 \%$, and the imbibition recovery of the surfactant with certain emulsifying ability is from $10 \%$ to $16 \%$. The emulsifying ability has no obviously effect on imbibition oil recovery. This may be caused by the small influence of the core size, which is not fully reflected in the emulsification.

\section{The new slick water system}

Volume fracturing is an important technology to realize the development of tight oil and gas reservoirs and shale gas reservoirs. The slickwater system is one of the key technologies, which includes friction reducer, surfactant, antiprecipitant, antiswelling agent, bactericide, and so on. The most important of these is the friction reducer. The commonly used friction reducers include polymer, melon gum, polyethylene oxide, surface active agent and so on. The slickwater system concludes many types of additives, leading to discontinuous mixing, complex technology and reservoir damage. It is necessary to develop a new slick water system realizing multiple functions.

\section{Synthesis}

Supramolecular chemistry is a hot spot in the field of chemistry in recent years. Supramolecular is usually a complex, organized aggregate that relies on intermolecular interactions (Fan Dehua forces, hydrogen bonds, etc.) together. It is a kind of compound that maintains a certain integrity to make it have a clear microscopic structure and macroscopic properties. It is realized the controllable regulation of the aggregation state in the aqueous solution and changed the rheological properties of the solution By controlling the change of the hydrophilic and hydrophobic proportion in the molecular chain. 
First, It is designed the synthesis of polymerizable surfactant monomer. Then the two parent polymer surfactants with certain molecular weight were synthesized by means of homopolymerization, copolymerization and polycondensation. Thus, the friction reducer, which has the functions of reducing friction and adjusting surface tension, is obtained. The molecular chains in the solution interact with each other through intermolecular forces such as Fan Dehua force, hydrogen bond and ionic bond to form a supramolecular threedimensional network structure that is covered with the entire solution system, so as to achieve high viscosity and friction reduction of low molecular system. In the synthesis process, the molecular weight of polymer synthesis process control is 1.5 millions and the degree of hydrolysis was $30 \%$. In order to improve the surface activity and fast dissolution performance, $15 \%$ silane coupling agent and 5\%12- allyl twelve alkyl sodium alkyl acid are added.

\section{Performance evaluation}

In volume fracturing process the amount of slickwater system is very large, at least several thousands of square, sometimes need tens of thousands. Therefore, its solubility must be considered. The solubility of slickwater is characterized by determination viscosity at different temperature with the dissolution time curves, fig.4.

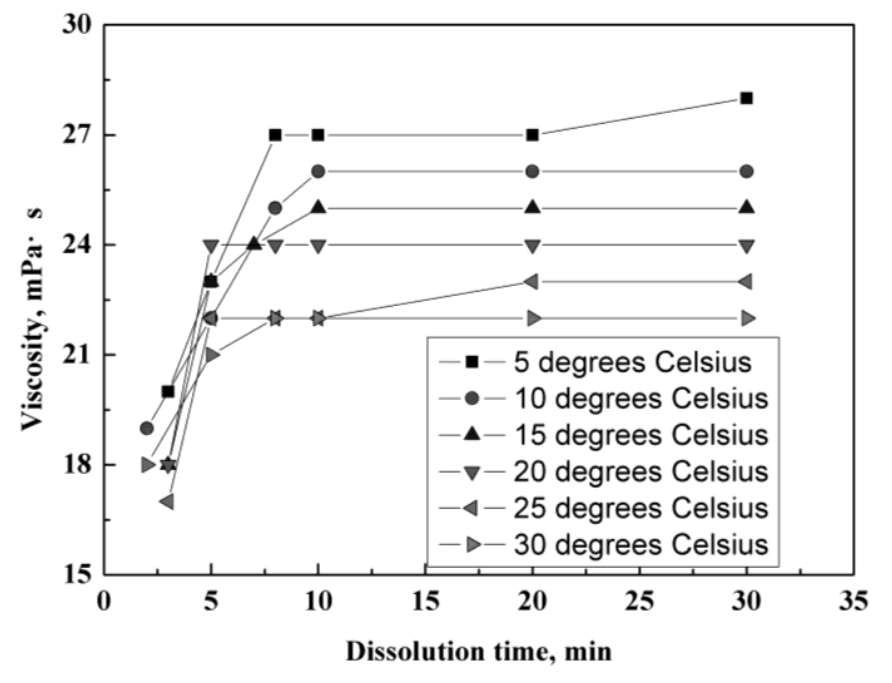

Fig. 4. the viscosity vs dissolution time

At the same temperature, with the prolongation of the dissolution time, the viscosity increases first and then tends to be stable. When the dissolution time is about 5 minutes, the viscosity of the system basically reaches a stable value. With the increase of temperature, the viscosity decreases gradually. And the viscosity of the system is greater than $20 \mathrm{mPa} \cdot \mathrm{s}$ in the range of $5^{\circ} \mathrm{C}$ to $30^{\circ} \mathrm{C}$.

The early slickwater does not contain the proppant, which leads to the poor conductivity of the created fractures. The field application and experiment show that the effect of the slickwater fracturing with proppant is better than that without proppant. This is because the proppant can keep the created fractures open after the slickwater returns. Temperature 
resistant and anti-shear ability of slickwater has become a very important technical index. Under the condition of $130^{\circ} \mathrm{C}$ and shear rate of $170 \mathrm{~s}^{-1}$, the change curve of viscosity with time is determined by HTHP rheometer, fig.5.

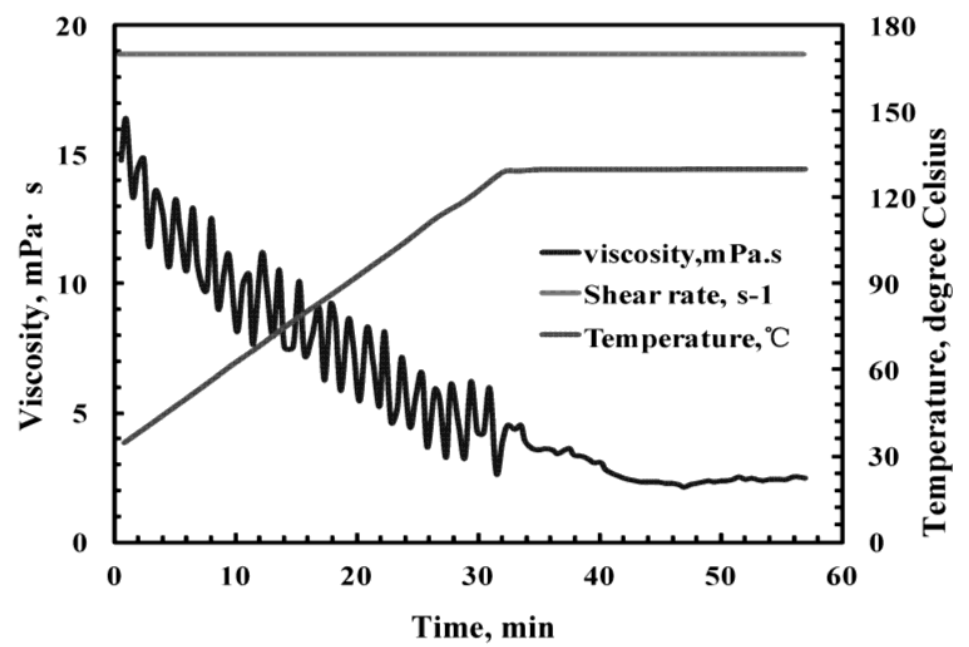

Fig. 5. the viscosity vs time under the shear rate of $170 \mathrm{~s}^{-1}, 130^{\circ} \mathrm{C}$

The viscosity decreases gradually with time prolong, from initial viscosity $15 \mathrm{mPa} \cdot \mathrm{s}$ to 2.3 $\mathrm{mPa} \cdot \mathrm{s}$. After 60 minutes shearing under $170 \mathrm{~s}^{-1}$, the final viscosity of slickwater water is 2.3 $\mathrm{mPa} \cdot \mathrm{s}$, meet the requirements of carrying proppant.

In addition to the role of constructing complex created fractures, slickwater also could supplement the formation energy, delay the production decline and enhance the imbibition oil recovery. The previous analysis shows that the interfacial tension and wettability have important effects on the imbibition oil recovery. The optimum interfacial tension value of slickwater is in the range of $10^{-1} \mathrm{mN} / \mathrm{m}$ magnitude, while could change the reservoir from the original state to water-wetting. Under the condition of $130^{\circ} \mathrm{C}$ and pressure of $10 \mathrm{MPa}$, the interfacial tension between slickwater and crude oil is determined as $0.45 \mathrm{mN} / \mathrm{m}$. At the sametime, the slickwater system could decrease the contact angle from $55^{\circ}$ to $22^{\circ}$. According to the capillary force formula, the novel slickwater system can effectively enhance the imbibition oil recovery.

The permeability and porosity of shale gas reservoirs or tight oil and gas reservoirs are very low. Tiny damage can greatly reduce the permeability of the reservoir and affect the production after fracturing. Reservoir damage rate is one of the important indicators of slickwater, which is evaluated by the core flow experiment, the steps as following: First, the oil phase permeability of the core is measured. Then, 1 pore volume of gel breaking liquid of slickwater is injected into the core. Finally, the oil phase permeability of the core is measured again at the same condition. The damage rate is difined as the ratio between the permeability difference before and after damage to the permeability before damage, fig.6. 


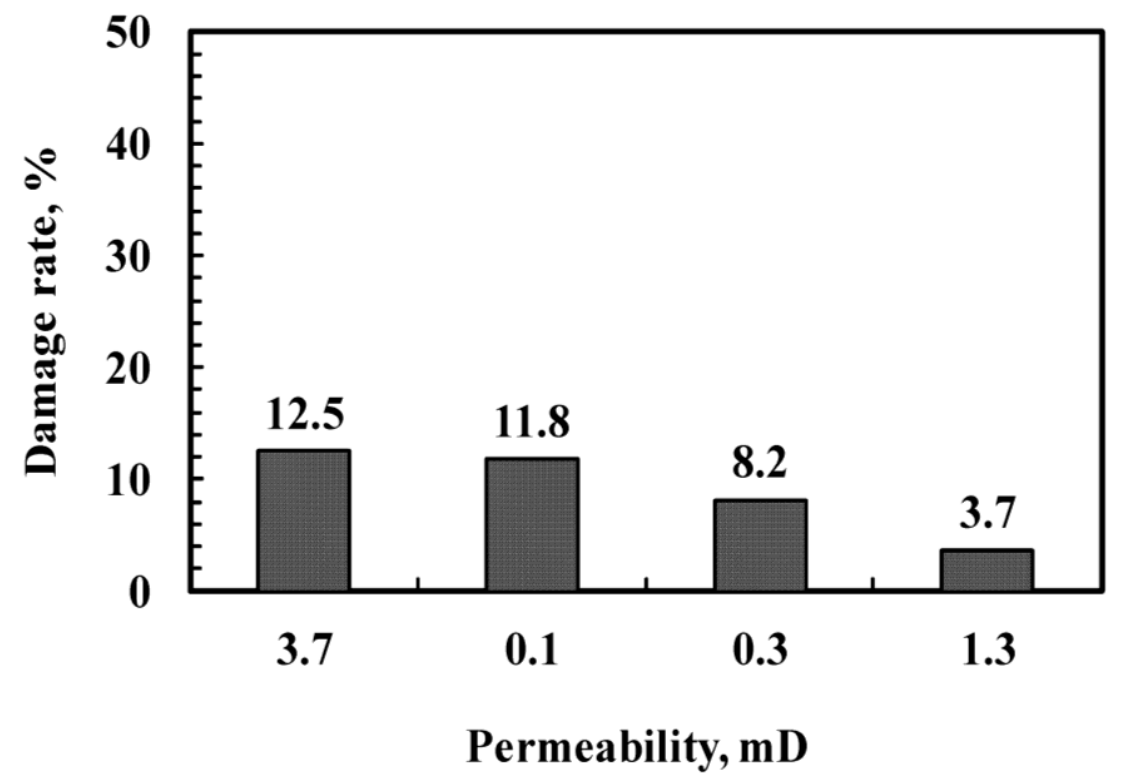

Fig. 6. the damage rate of core sample vs permeability

When the core peameability is less than $3.7 \mathrm{mD}$, the damage rate is smaller than $12.5 \%$. The molecular weight of friction reducer in slickwater system is approximately 1.5 millions, which is smaller than other friction reducer. The weight average molecular weight and the number average molecular weight of the gel breaking liquid is determined by gel chromatography, which are 114 thousand and 48 thousand respectively. The slickwater system antiswelling rate is as high as $85 \%$, which could effectively prevent clay expansion and migration and reduce reservoir damage.

According to the steps of the static imbibition experiment, the imbibition oil recovery of the novel slick water is measured as $43 \%$, which is higher than normal surfactants. The used natural core permeability is about $1 \mathrm{mD}$.

\section{Field Application}

The low permeable reservoir of Eogene system in Jidong oilfield is a sandstone reservoir, which is mainly distributed in the Shahejie Formation. The characteristics of the reservoir are buried deeply, small scale for individual sand body, discontinuous both horizontally and longitudinally, worse for sand body interconnection. The direction of the ground stress is from the North East to the South West, the two direction stress difference is big and the natural fracture is not developed.

The slickwater fracturing technology is adapted in the lower permeability, smaller two direction stress difference, higher brittle mineral content and developed several natural fractures. The permeability of the fractured zone is less than $3 \mathrm{mD}$, the two direction stress 
difference is about $10 \mathrm{MPa}$, and the brittle mineral content is $80 \%$. The average fracture density of the rock core is $0.81 \mathrm{strip} / \mathrm{m}$, and the difference between the plane and the vertical is great, and the heterogeneity of the fracture development is strong. The reservoir parameters of fractured well are shown in table 1.

Table 1. Reservoir parameter table of fractured well

\begin{tabular}{|c|c|c|c|c|c|c|c|}
\hline $\begin{array}{l}\text { Well } \\
\text { No. }\end{array}$ & $\begin{array}{c}\text { Burie } \\
\mathrm{d} \\
\text { depth, } \\
\mathrm{m}\end{array}$ & $\begin{array}{l}\text { Thickne } \\
\text { ss of oil } \\
\text { layer,m }\end{array}$ & $\begin{array}{c}\text { porosity, } \\
\%\end{array}$ & $\begin{array}{c}\text { permeability,m } \\
\text { D }\end{array}$ & $\begin{array}{c}\text { oil } \\
\text { saturation, } \\
\%\end{array}$ & $\begin{array}{c}\text { shale } \\
\text { content, } \\
\%\end{array}$ & $\begin{array}{c}\text { pressure } \\
\text { coefficie } \\
\text { nt }\end{array}$ \\
\hline JD1 & 4323 & 8 & 11.8 & 3.1 & 52.6 & 10 & 1.3 \\
\hline JD2 & 3745 & 17.6 & 10.45 & 1.28 & 55 & 17.38 & 1.1 \\
\hline JD3 & 4029 & 14.2 & 11.7 & 2.08 & 54.43 & 11.31 & 1.39 \\
\hline
\end{tabular}

The fracturing process includes slickwater stage and linear gel stage. In the slickwater stage, 10\% 100 mesh ceramists and 8\% temporary plugging agents are carried into the formation by functional slick water. $2000 \mathrm{~m}^{3}$ slickwater is used in this stage. In the linear gel stage, $40-70$ mesh ceramists are carried by linear gel and about $500 \mathrm{~m}^{3}$ linear gel is used in this stage. The liquid volume ratio is about $4: 1$ and the displacement is controlled at 10$12 \mathrm{~m}^{3} / \mathrm{min}$. The sand content and fracturing fluid volume of single stage are $80 \mathrm{~m}^{3}$ and 2500 $\mathrm{m}^{3}$ respectively. The construction pressure is distributed in 55-73MPa. Compared with the conventional fracturing technology, the construction pressure is large $8-10 \mathrm{MPa}$ in the same reservoir.

Flowback after fracturing can be seen that flowback pressure is higher $5 \mathrm{MPa}$ than that of conventional fracturing. Due to imbibition oil recovery, there is only $25 \%$ of the fracturing fluid flowback rate when the crude oil flowed out. While when the crude oil flowed out, the fracturing fluid flowback rate is as high as $46.4 \%$ after conventional fracturing. The novel slickwater has suitable interfacial tension and change reservoir wettability ability, which could improve the imbibition recovery to a great extent. When the oil well is in normal production, about $50 \%$ of the fracturing fluid is not returned. The normal production is in the stage of stable water cut and daily fluid production rate. Under the action of the capillary force, slickwater and crude oil replacement to enhance imbibition recovery. And the slickwater stores in the reservoir instead of crude oil. It is useful to maintain the formation energy and slow down the production decline. The cumulative oil production is counted every 90 days, and the results showed that the output of oil well does not decrease significantly in 1 year. The average cumulative production of vertical wells is greater than $2800 \mathrm{t}$. The highest cumulative oil production has reached $4800 \mathrm{t}$. And the effective period is more than 2 years.

This technology overcoming the problem of high horizontal stress difference and lack of natural fracture has been successfully applied in Jidong Oilfield ultralow permeability reservoir. The successful application of this technology not only helps to promote the 
effective use of ultralow permeability reservoirs, but also helps to further clarify the role of imbibition recovery, energy storage and oil-water replacement mechanism.

\section{Conclusion}

The imbibition effect plays an important role in the development of tight oil and gas reservoirs. The following conclusions are obtained through experiment research and field application:

(1) The imbibition oil recovery is effected by the surfactant of slickwater system. The surfactant with suitable interfacial tension and a certain ability to change wettability can effectively improve the imbibition recovery.

(2) Slickwater system is an important component of fracturing technology. Multifunctional slickwater is one of the future direction of technology development. The slickwater with friction effect, interfacial activity, antiswelling effect can simplify the process, improve the imbibition recovery. That is an effective technology to achieve the benefit development of tight oil and gas reservoirs.

(3) The field application shows that a suitable slickwater can reduce the fracturing fluid flowback rate, which can realize energy supplement and enhance the imbibition oil recovery.

\section{Acknowledgements}

This work is sponsored by the Opening Fund of Shandong Key Laboratory of Oilfield Chemistry, the Fundamental Research Funds for the Central Universities (19CX05006A), Major Projects of Chemistry Flooding in Jidong Oilfield (NO. KF2018A03-04) of research and Application of Chemistry Flooding in High Temperature Reservoir.

\section{References}

1. M. J. Mayerhofer, M. F. Richardson, R. N. Walker, et al. Proppants? We don't need no proppants (Annual Technical Conference and Exhibition, San Antonio, Texas 1997)

2. G. Schein, The Application and technology of slickwater fracturing[J]. SPE-108807-DL (2005)

3. G. R. Coulter, E. G. Benton, C. L. Thomson, Water fracs and sand quantity: a Barnett shale example (Annual Technical Conference and Exhibition, Houston, Texas, 2004)

4. M. B. Brittlk, Smith, Z. Haddad, Water-fracs: we do need proppant after all (SPE Annual Technical Conference and Exhibition, San Antonio, Texas, 2006)

5. A. J. Daniel, B. Bohm, B. J. Coughlin, Evaluating implications of hydraulic fracturing in shale gas reservoirs (SPE Americas E\&P Environmental and Safety Conference, San Antonio, Texas, 2009)

6. P. J. Shuler, H. Tang, Z. Lu, Chemical process for improved oil recovery from Bakken shale (Canadian Unconventional Resources Conference, Calgary, Alberta, 2011)

7. D. Wang, R. Seright, J. Zhang, Wettability survey in Bakken shale with surfactantformulation imbibition (SPE Improved Oil Recovery Symposium, Tulsa, Oklahoma, 2012) 
8. V. Mirchi, S. Saraji, L. Goual, Dynamic interfacial tensions and contact angles of surfactant-in-brine/oil/shale systems: Implications to enhanced oil recovery in shale oil reservoirs (SPE Improved Oil Recovery Symposium, Tulsa, Oklahoma, 2014)

9. V. Mirchi, S. Saraji, L. Goual, Experimental investigation of surfactant flooding in shale oil reservoirs: Dynamic interfacial tension, adsorption, and wettability (Unconventional Resources Technology Conference, Denver, Colorado, 2014)

10. D. C. Standnes, T. Austad, Presented at the Journal of Petroleum Science \& Engineering, 28:3, 123 (2000)

11. R. Yanjun, J. Guancheng, Zh. Dujian, Presented at the Petroleum Exploration and Development, 42:1, 125 (2015)

12. K. Kumar E. Dao, K. Mohanty, SPE Journal, 13:13, 137 (2008)

13. T. Al-Wahaibi, A. Abubakar, A. Al-Hashmi, Journal of Petroleum Science \& Engineering, 20:1, 315 (2016)

14. K. Ellina, O. Gabriel, J. H. David, Journal of Polymer Research, 21, 212 (2015)

15. S. Ummartyotin, N. Bunnak, H. Manuspiya, Renewable \& Sustainable Energy Reviews, 61, 466 (2016)

16. A. Hayder, A. Bari, E. O. Akindoyo, Presented at the Journal of Fluid Mechanics, 4:2, $84(2015)$ 